Article

\title{
Applications of Copolymers Consisting of 2,6-di(9H-carbazol-9-yl)pyridine and 3,6-di(2-thienyl)carbazole Units as Electrodes in Electrochromic Devices
}

\author{
Chung-Wen Kuo ${ }^{1}$, Jui-Cheng Chang ${ }^{2}$, Yu-Ting Huang ${ }^{1}$, Jeng-Kuei Chang ${ }^{3}{ }^{\circledR}$, Li-Ting Lee ${ }^{4}$ and \\ Tzi-Yi Wu ${ }^{5, *(D)}$ \\ 1 Department of Chemical and Materials Engineering, National Kaohsiung University of Science and \\ Technology, Kaohsiung 80778, Taiwan; welly@nkust.edu.tw (C.-W.K.); a3473179@gmail.com (Y.-T.H.) \\ 2 Bachelor Program in Interdisciplinary Studies, National Yunlin University of Science and Technology, \\ Yunlin 64002, Taiwan; d700215@gmail.com \\ 3 Department of Materials Science and Engineering, National Chiao Tung University, Hsinchu 30010, Taiwan; \\ jkchang@nctu.edu.tw \\ 4 Department of Materials Science and Engineering, Feng Chia University, Taichung 40724, Taiwan; \\ ltlee@fcu.edu.tw \\ 5 Department of Chemical Engineering and Materials Engineering, National Yunlin University of Science and \\ Technology, Yunlin 64002, Taiwan \\ * Correspondence: wuty@gemail.yuntech.edu.tw
}

Received: 14 March 2019; Accepted: 12 April 2019; Published: 16 April 2019

\begin{abstract}
A series of carbazole-based polymers (PdCz, P(dCz2-co-dTC1), P(dCz2-co-dTC2), $\mathrm{P}(\mathrm{dCz} 1-c o-\mathrm{dTC} 2)$, and PdTC) were deposited on indium tin oxide (ITO) conductive electrodes using electrochemical polymerization. The as-prepared $\mathrm{P}(\mathrm{dCz} 2-\mathrm{co}-\mathrm{dTC} 2)$ displayed a high $\Delta T(57.0 \%)$ and multichromic behaviors ranging from yellowish green, greenish gray, gray to purplish gray in different redox states. Five organic electrochromic devices (ECDs) were built using dCz- and dTC-containing homopolymers and copolymers as anodic materials, and poly(3,4-(2,2-dimethylpropylenedioxy)thiophene) (PProdot-Me $\mathrm{M}_{2}$ ) as the cathodic material. The $\mathrm{P}(\mathrm{dCz} 2-\mathrm{co}-\mathrm{dTC} 2) / \mathrm{PProdot}-\mathrm{Me}_{2}$ ECD presented remarkable electrochromic behaviors from the bleached to colored states. Moreover, $\mathrm{P}(\mathrm{dCz} 2-\mathrm{co}-\mathrm{dTC} 2) / \mathrm{PProdot}_{\mathrm{Me}}$ ECD displayed a high optical contrast $(\Delta T, 45.8 \%$ ), short switching time (ca. $0.3 \mathrm{~s})$, high coloration efficiency $\left(528.8 \mathrm{~cm}^{2} \mathrm{C}^{-1}\right)$ at $580 \mathrm{~nm}$, and high redox cycling stability.
\end{abstract}

Keywords: copolymer; electrochromic material; spectroelectrochemistry; coloration efficiency; electrochromic device; redox stability

\section{Introduction}

Over the past numerous years, several inorganic and organic electrochromic materials have been extensively studied for use in the rear-view mirrors of vehicles, displays, helmet visors, and windows of buildings [1]. In these electrochromic materials, reversible redox reactions lead to an important change in transmitted (or reflected) light. The promising inorganic electrochromic materials are transition metal oxides (e.g., $\mathrm{WO}_{3}, \mathrm{Ta}_{2} \mathrm{O}_{5}, \mathrm{TiO}_{2}, \mathrm{Nb}_{2} \mathrm{O}_{5}$, and $\mathrm{MoO}_{3}$ ), whereas the potential organic electrochromic materials are $\pi$-conjugated polymers, viologen derivatives, metallophthalocyanines, and metallopolymers [2]. Among these organic electrochromic materials, recent research has concentrated interest on the applications of conjugated polymers as electrochromic (EC) electrodes due to their fast-electrochromic switching time [3], satisfactory coloration efficiency [4], and wide color availability through the chemical structures modification [5]. The organic EC 
materials are particularly polyaniline [6], polytriphenylamine [7], polyindole [8], polycarbazole [9], polypyrrole [10], polythiophene [11], polyselenophene [12], poly(3,4-ethylenedioxythiophene) (PEDOT) [13], and polyanthracene [14]. Polytriphenylamine, polycarbazole and their derivatives have been broadly used for numerous optical and electrochemical devices due to their good hole-transporting/mobile abilities and high thermal stability $[15,16]$. The redox peaks and electrochromic behaviors of polytriphenylamine and polycarbazole depend on the types and number of substituents, which contain electron-donating and electron-withdrawing units. Ak et al. reported on the electrochromic behaviors of a carbazole based star shaped polymer (PTPC). The PTPC displayed absorption peaks at 308,460 , and $780 \mathrm{~nm}$, which are in agreement with the $\pi-\pi^{*}$ transition peak, polaron band, and bipolaron band of the PTPC, respectively. The PTPC film was green in its oxidized state and transparent in its reduced state [17]. Zhang et al. reported the preparation and electrochromic characterizations of a triphenylamine-, carbazole-, and EDOT-containing electrochromic copolymer film (P(CDPN-co-EDOT)) [18]. The P(CDPN-co-EDOT) film displayed four kinds of colors (claret red, green, cadetblue, and blue) from the neutral state to the oxidized state. The $\Delta T$ of $\mathrm{P}(\mathrm{CDPN}$-co-EDOT) was $36 \%$ and $43 \%$ in visible zone and near-IR region, respectively. Polythiophene and its derivatives are widely studied owing to their interesting characteristics such as narrow band gaps and desirable stability in air [19]. However, the onset oxidation potentials of polythiophene films are high [20]. Reynolds et al. synthesized the EDOT analogs such as 3,4-propylenedioxythiophene (ProDOT) and EDOT-Me and investigated the electrochromic properties of their corresponding PProDOT and PEDOT-Me polymer films, which displayed lower onset oxidation potentials than those of polythiophene films. The $\Delta T$ of these PEDOT derivatives were $44-63 \%$ at ca. $590 \mathrm{~nm}$ [21]. Since PProDOT film displays no significant absorption band in UV-Vis zone in oxidized state and the color is dark blue in reduced state, PProDOT is a potential cathodic material of electrochromic devices (ECDs). Moreover, vapor phase polymerization (VPP) and oxidative chemical vapor deposition (oCVD) are also widely used in synthesis of conjugated polymers [22,23].

In the present study, two homopolymers (PdCz and PdTC) and three copolymers (P(dCz2-co-dTC1), $\mathrm{P}(\mathrm{dCz}$-co-dTC2), $\mathrm{P}(\mathrm{dCz} 1-c o-\mathrm{dTC} 2))$ with different dCz/dTC feed molar ratios were electrosynthesized to study their potential applications in ECDs. 2,6-di(9H-carbazol-9-yl)pyridine unit comprises two carbazole groups linked by a pyridine core, such donor-acceptor-donor (D-A-D) configuration is efficient for narrowing the band gap of polymers. Moreover, two carbazole groups in each repeat unit of polymer backbone facilitate the formation of radical cations and dication upon oxidation. In addition, the chemical structure of 3,6-di(2-thienyl)carbazole group displays that a carbazole unit inserts between two thiophene units, PdTC is easier to oxidize due to the donor capability of the carbazole. Poly(3,6-carbazole) has been shown to have a short conjugation length. The incorporation of thiophenes at 3,6-positions of carbazole unit would extend this conjugation length, leading to low oxidation potentials. Furthermore, five ECDs consisted of PdCz, P(dCz2-co-dTC1), P(dCz2-co-dTC2), $\mathrm{P}(\mathrm{dCz} 1-\mathrm{co}-\mathrm{dTC} 2)$, or PdTC as the anodic material, and PProdot-Me $\mathrm{M}_{2}$ as the cathodic material were fabricated and their spectroelectrochemical characteristics, transmittance-time profiles, and long-term electrochemical stability were studied in detail.

\section{Experimental}

\subsection{Materials}

2,6-di(9H-carbazol-9-yl)pyridine (dCz), 3,6-di(2-thienyl)carbazole (dTC), and Prodot- $\mathrm{Me}_{2}$ were prepared according to previously published methods [24,25]. Electrolytes of electrochromic devices were prepared using poly(methyl methacrylate) (PMMA):propylene carbonate (PC): $\mathrm{LiClO}_{4}$ in a weight ratio of 33:53:14 [26]. 
2.2. Electrochemical Preparation of $P d C z, P(d C z 2-c o-d T C 1), P(d C z 2-c o-d T C 2), P(d C z 1-c o-d T C 2), P d T C$, and PProdot-Me $\mathrm{M}_{2}$ Films

The electrosynthesis of PdCz, P(dCz2-co-dTC1), P(dCz2-co-dTC2), P(dCz1-co-dTC2), and PdTC films were carried out in an $0.2 \mathrm{M} \mathrm{LiClO}_{4}$ /acetonitrile (ACN)/dichloromethane (DCM) (1:1, by volume) solution, and the feed ratio of species for anodic polymer films were listed in Table 1 . The carbazole-based polymer films were electrodeposited potentiodynamically by sweeping voltages in a range of $0.0-1.4 \mathrm{~V}$ (vs. $\mathrm{Ag} / \mathrm{AgNO}_{3}$ ) for 3 cycles. The $\mathrm{Ag} / \mathrm{AgNO}_{3}$ electrode was calibrated using ferrocene. PProdot-Me film was electrodeposited potentiostatically at $1.0 \mathrm{~V}$ (vs. $\mathrm{Ag} / \mathrm{AgNO}_{3}$ ). Polymeric thicknesses at the electrode surfaces obtained from an Alpha-Step profilometer (KLA Tencor D-120, Milpitas, CA, USA) were about $180-300 \mathrm{~nm}$.

Table 1. Feed species and molar ratio of anodic polymer electrodes (a)-(e).

\begin{tabular}{cccc}
\hline Electrodes & Anodic Polymer & Feed Species of Anodic Polymer & Feed Molar Ratio of Anodic Polymer \\
\hline (a) & $\mathrm{PdCz}$ & $2 \mathrm{mM} \mathrm{dCz}$ & Neat dCz \\
(b) & $\mathrm{P}(\mathrm{dCz} 2-c o-d T C 1)$ & $2 \mathrm{mM} \mathrm{dCz}+1 \mathrm{mM} \mathrm{dTC}$ & $2: 1$ \\
(c) & $\mathrm{P}(\mathrm{dCz}-\mathrm{co}-\mathrm{dTC})$ & $2 \mathrm{mM} \mathrm{dCz}+2 \mathrm{mM} \mathrm{dTC}$ & $2: 2$ \\
(d) & $\mathrm{P}(\mathrm{dCz} 1-c o-d T C 2)$ & $1 \mathrm{mM} \mathrm{dCz}+2 \mathrm{mM} \mathrm{dTC}$ & $1: 2$ \\
(e) & PdTC & $2 \mathrm{mM} \mathrm{dTC}$ & Neat dTC \\
\hline
\end{tabular}

\subsection{Fabrication of Electrochromic Devices}

ECDs were constructed using PdCz, P(dCz2-co-dTC1), P(dCz2-co-dTC2), P(dCz1-co-dTC2), or PdTC film as the anodic layer and PProdot-Me $\mathrm{M}_{2}$ film as the cathodic layer. The active areas of anode and cathode were $1.5 \mathrm{~cm}^{2}$. The ECDs were built by arranging the reduced and oxidized polymeric films to face each other, and they were isolated by a PMMA/PC/ACN/LiClO 4 composite electrolyte.

\subsection{Characterizations of Polymer Films and ECDs}

The as-prepared polymer films and ECDs were characterized using a CHI627D electrochemical analyzer (CH Instruments, Austin, TX, USA) and an Agilent Cary 60 UV-Visible spectrophotometer (Varian Inc., Walnut Creek, CA, USA). The system of electrochemical experiments was implemented in a three-constituent cell. The working electrode was an ITO coated glass plate, the counter electrode was a platinum wire, and an $\mathrm{Ag} / \mathrm{AgNO}_{3}$ electrode was used as the reference electrode. Spectroelectrochemical experiments were monitored using a spectrophotometer, the spectroelectrochemical characterizations of polymer films were performed in a UV quartz cuvette cell (Varian Inc., Walnut Creek, CA, USA), and the path length of cell was $1 \mathrm{~cm}$.

\section{Results and Discussion}

\subsection{Electrochemical Polymerization and FT-IR Characterization}

Figure 1 displays the cyclic voltammograms (CV) of $2 \mathrm{mM} \mathrm{dCz}, 2 \mathrm{mM} \mathrm{dTC}$, and their mixtures ( $2 \mathrm{mM} \mathrm{dCz}+1 \mathrm{mM} \mathrm{dTC} ; 2 \mathrm{mM} \mathrm{dCz}+2 \mathrm{mM} \mathrm{dTC} ; 1 \mathrm{mM} \mathrm{dCz}+2 \mathrm{mM} \mathrm{dTC})$ in $0.2 \mathrm{M} \mathrm{LiClO}_{4} / \mathrm{ACN} / \mathrm{DCM}$ solution in the potential range from 0.0 to $1.4 \mathrm{~V}$. The scan rate was $100 \mathrm{mV} \mathrm{s}^{-1}$. When the number of $\mathrm{CV}$ cycles increased, the current density of redox peaks increased with an increasing scanning number, implying the growth of polymer films on ITO surfaces [27]. As displayed in Figure 1a, the 1st and 2nd oxidation peaks of $\mathrm{PdCz}$ at ca. 0.87 and $1.30 \mathrm{~V}$ (vs. $\mathrm{Ag} / \mathrm{AgNO}_{3}$ ), respectively, can be ascribed to the presence of radical cation and dication in a $\mathrm{dCz}$ unit. The CV curves of PdTC show an oxidation and a reduction peaks at 1.05 and $0.37 \mathrm{~V}$, respectively, as shown in Figure 1e. The electrochemical redox peaks of PdCz and PdTC were quasi-reversible. When the CV curves were swept in the mixture of $\mathrm{dCz}$ and $\mathrm{dTC}$ monomers, the oxidation peaks of $\mathrm{P}(\mathrm{dCz} 2-c o-\mathrm{dTC} 1), \mathrm{P}(\mathrm{dCz} 2-\mathrm{co}-\mathrm{dTC} 2)$, and $\mathrm{P}(\mathrm{dCz} 1-\mathrm{co}-\mathrm{dTC} 2)$ appeared at $1.25,1.19$ and $1.15 \mathrm{~V}$, respectively, and the reduction peaks of $\mathrm{P}(\mathrm{dCz} 2-\mathrm{co}-\mathrm{dTC} 1), \mathrm{P}(\mathrm{dCz} 2-\mathrm{co}-\mathrm{dTC} 2)$, and $\mathrm{P}(\mathrm{dCz} 1-\mathrm{co}-\mathrm{dTC})$ located at $0.50,0.43$ and $0.39 \mathrm{~V}$, respectively, as shown in Figure $1 \mathrm{~b}-\mathrm{d}$. The redox 
potentials and wave shapes of copolymers are different from those of homopolymers, and this is an evidence of the copolymerization of $\mathrm{P}(\mathrm{dCz} 2-\mathrm{co}-\mathrm{dTC} 1), \mathrm{P}(\mathrm{dCz} 2-\mathrm{co}-\mathrm{dTC} 2)$, and $\mathrm{P}(\mathrm{dCz} 1-\mathrm{co}-\mathrm{dTC} 2)$ films. The polymer films were further characterized using FT-IR, Figure 2 displayed the FT-IR spectra of electrochemically synthesized PdCz, P(dCz2-co-dTC1), P(dCz2-co-dTC2), P(dCz1-co-dTC2), and PdTC films. The characteristic peaks of PdCz are shown in Figure 2a. The characteristic band at $1095 \mathrm{~cm}^{-1}$ indicates the doping of $\mathrm{PdCz}$ film with the $\mathrm{ClO}_{4}{ }^{-}$. The characteristic peaks at around $1600 \mathrm{~cm}^{-1}$ represent the aromatic $C=C$ stretching vibration. The band at $1220 \mathrm{~cm}^{-1}$ is related to $C-C$ formation. The peak at around $1450 \mathrm{~cm}^{-1}$ can be ascribed to the $\mathrm{C}-\mathrm{N}$ stretching of the carbazole unit [28].
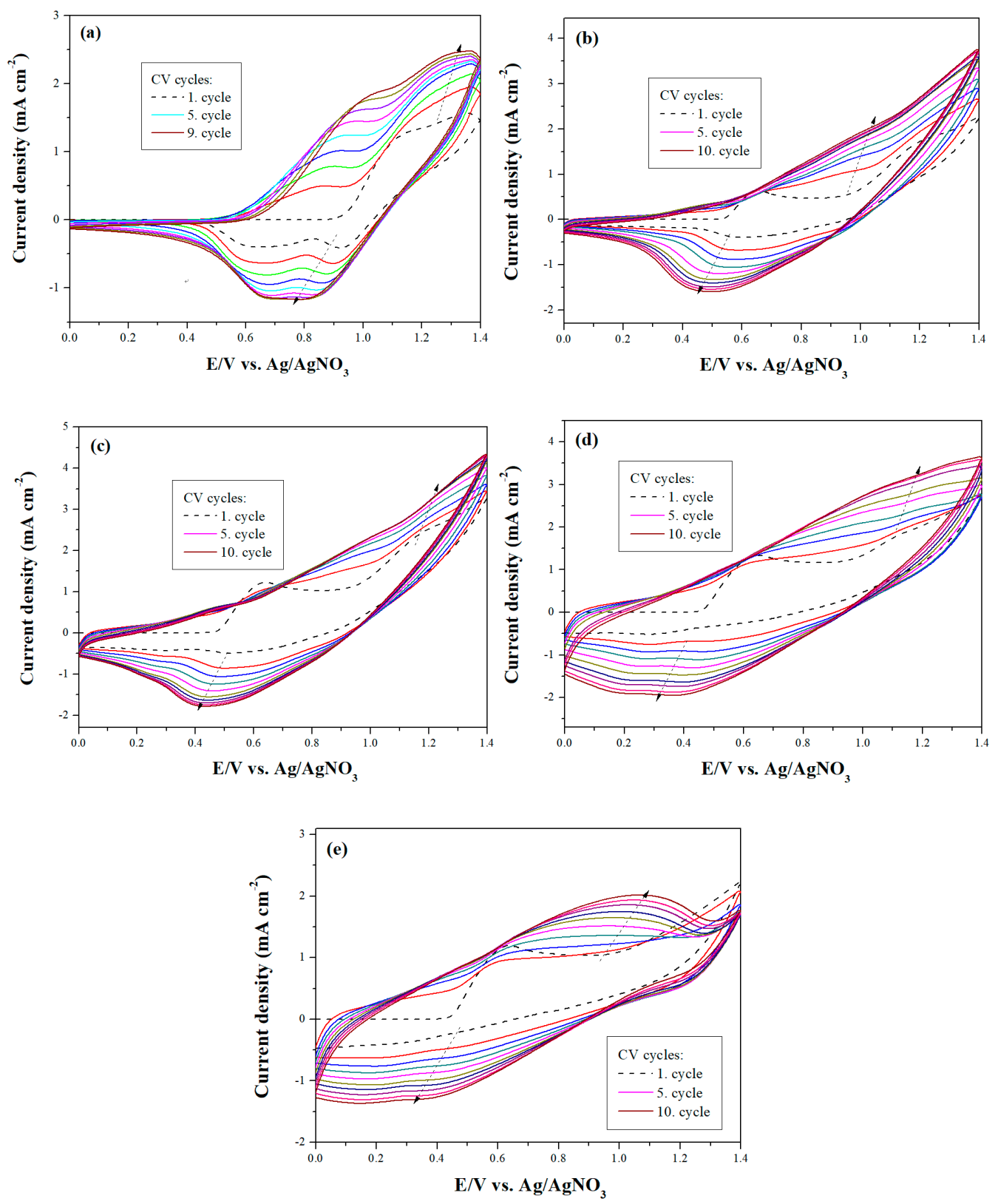

Figure 1. Electrochemical synthesis of (a) PdCz; (b) $\mathrm{P}(\mathrm{dCz} 2-c o-d T C 1)$; (c) $\mathrm{P}(\mathrm{dCz} 2-\mathrm{co}-\mathrm{dTC} 2)$; (d) P(dCz1-co-dTC2) and (e) PdTC in ACN/DCM (1:1, by volume) solution at $100 \mathrm{mV} \mathrm{s}^{-1}$ on ITO working electrodes. 


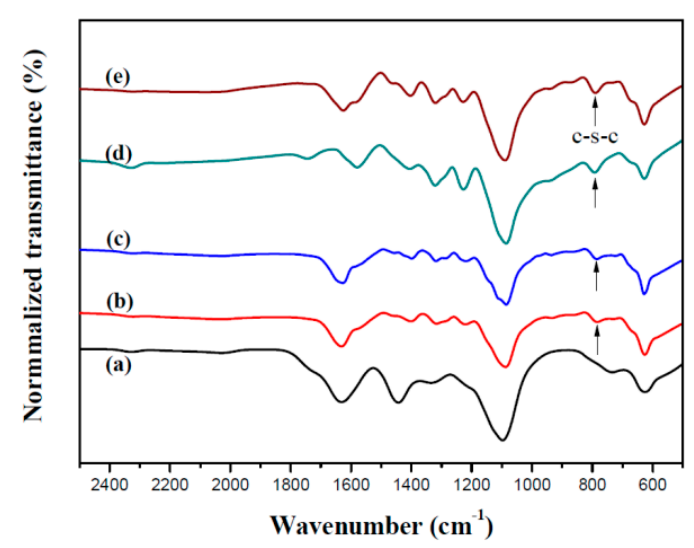

Figure 2. FT-IR spectra of (a) PdCz; (b) P(dCz2-co-dTC1); (c) P(dCz2-co-dTC2); (d) P(dCz1-co-dTC2) and (e) PdTC.

There was no conspicuous characteristic peak of PdCz at ca. $790 \mathrm{~cm}^{-1}$ as shown in Figure 2a. Figure $2 b-d$ not only revealed the characteristic peaks of $\mathrm{PdC} z$ but also displayed the characteristic peak (-C-S-C- stretching) of PdTC, the formation of a new characteristic peak at $790 \mathrm{~cm}^{-1}$ could be attributed to the presence of dTC in $\mathrm{P}(\mathrm{dCz} 2-c o-\mathrm{dTC} 1), \mathrm{P}(\mathrm{dCz} 2-\mathrm{co}-\mathrm{dTC} 2)$, and $\mathrm{P}(\mathrm{dCz} 1-\mathrm{co}-\mathrm{dTC} 2)$ films, implying $\mathrm{dCz}$ - and dTC-containing copolymer films were successfully synthesized. The polymerization schemes of PdCz, P(dCz-co-dTC), and PdTC are shown in Figure 3.

(a)<smiles></smiles>

$\mathrm{dCz}$

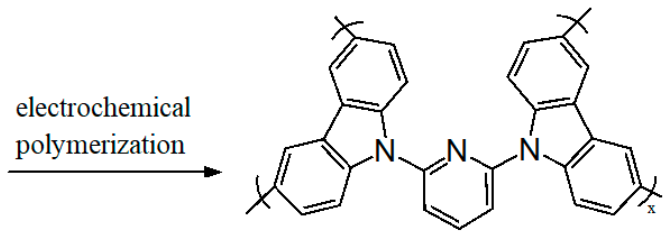

$\mathrm{PdCZ}$

(b)<smiles></smiles>

$\mathrm{dCz}$<smiles>c1csc(-c2ccc3[nH]c4ccc(-c5cccs5)cc4c3c2)c1</smiles>

dTC

electrochemical polymerization

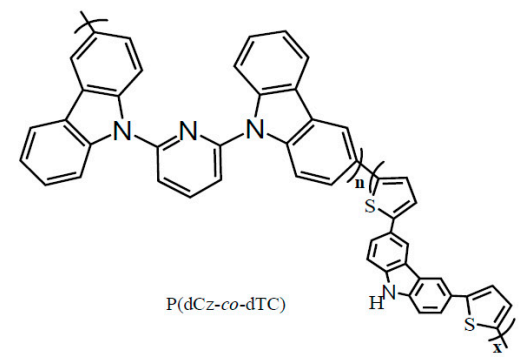

(c)<smiles>c1csc(-c2ccc3c(c2)[nH]c2ccc(-c4cccs4)cc23)c1</smiles>

dTC electrochemical polymerization
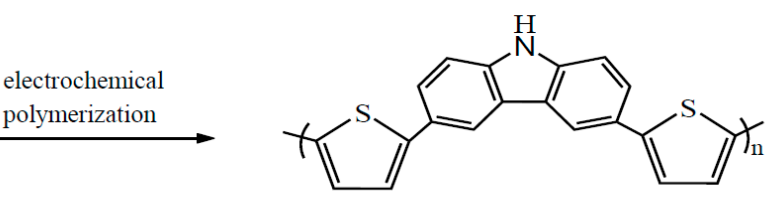

PdTC

Figure 3. The electrochemical polymerization routes of (a) PdCz; (b) P(dCz-co-dTC) and (c) PdTC. 


\subsection{Electrochemical Properties of Polymer Films}

The first rinse $\mathrm{P}(\mathrm{dCz} 2-\mathrm{co}-\mathrm{dTC} 2)$ film was immersed into clean electrolyte solution, and then run in new CV curves. The as-prepared P(dCz2-co-dTC2) film was swept at 10, 50, 100, 150, and $200 \mathrm{mV}$ $\mathrm{s}^{-1}$ in $0.2 \mathrm{M} \mathrm{LiClO}_{4} / \mathrm{ACN} / \mathrm{DCM}$ using CV. As shown in Figure 4, the anodic and cathodic peaks of $\mathrm{P}(\mathrm{dCz} 2-\mathrm{co}-\mathrm{dTC} 2)$ film showed a single quasi-reversible redox process and the anodic and cathodic peak current densities increased linearly with increasing scan rate (inset in Figure 4), implying the redox process of $\mathrm{P}(\mathrm{dCz} 2-\mathrm{co}-\mathrm{dTC})$ film was not a diffusion-controlled process [29].

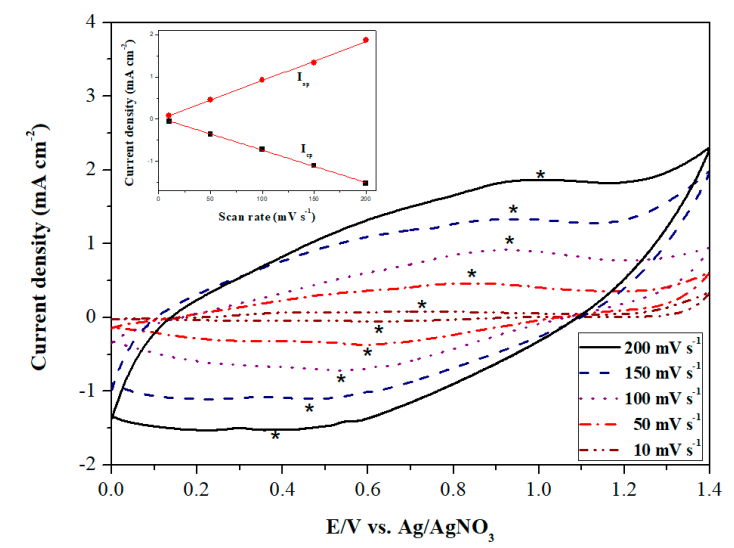

Figure 4. Cyclic voltammograms $(\mathrm{CV})$ curves of the $\mathrm{P}(\mathrm{dCz} 2-\mathrm{co}-\mathrm{dTC} 2)$ film at different scan rates between 10 and $200 \mathrm{mV} \mathrm{s}^{-1}$ in the $\mathrm{LiClO}_{4} / \mathrm{ACN} / \mathrm{DCM}$ solution. Inset is scan rate dependence of the $\mathrm{P}(\mathrm{dCz} 2-\mathrm{co}-\mathrm{dTC} 2)$ anodic and cathodic peak current densities.

\subsection{Spectroelectrochemical Investigation of Polymer Films}

Figure 5 shows UV-Visible spectra of PdCz, P(dCz2-co-dTC1), P(dCz2-co-dTC2), P(dCz1-co-dTC2), and PdTC electrodes in an ACN/DCM solution containing $0.2 \mathrm{M} \mathrm{LiClO}_{4}$. PdCz does not show distinct absorption peaks at $0.0 \mathrm{~V}$ but two new peaks appear at 430 and $785 \mathrm{~nm}$ gradually upon increasing of the applied potential, which can be attributed to the growth of charge carrier bands [30]. On the other hand, $\mathrm{P}(\mathrm{dCz} 2-\mathrm{co}-\mathrm{dTC} 1), \mathrm{P}(\mathrm{dCz} 2-\mathrm{co}-\mathrm{dTC} 2), \mathrm{P}(\mathrm{dCz} 1-\mathrm{co}-\mathrm{dTC} 2)$, and PdTC electrodes display absorption peaks at $406,410,405$, and $402 \mathrm{~nm}$ at $0.0 \mathrm{~V}$, respectively, which can be assigned to the $\pi-\pi^{*}$ transition of $\mathrm{P}(\mathrm{dCz} 2-\mathrm{co}-\mathrm{dTC} 1), \mathrm{P}(\mathrm{dCz} 2-c o-\mathrm{dTC} 2), \mathrm{P}(\mathrm{dCz} 1-\mathrm{co}-\mathrm{dTC} 2)$, and PdTC electrodes in their reduced state. When potentials in the oxidative direction were applied, the $\pi-\pi^{*}$ transition bands of $\mathrm{P}(\mathrm{dCz} 2-\mathrm{co}-\mathrm{dTC} 1)$, $\mathrm{P}(\mathrm{dCz} 2-\mathrm{co}-\mathrm{dTC} 2), \mathrm{P}(\mathrm{dCz} 1-\mathrm{co}-\mathrm{dTC} 2)$, and PdTC electrodes waned and new charge carrier bands $(550 \mathrm{~nm}$ and $860 \mathrm{~nm}$ for $\mathrm{P}(\mathrm{dCz} 2-c o-\mathrm{dTC} 1) ; 545 \mathrm{~nm}$ and $820 \mathrm{~nm}$ for $\mathrm{P}(\mathrm{dCz} 2-c o-\mathrm{dTC} 2) ; 548 \mathrm{~nm}$ and $830 \mathrm{~nm}$ for $\mathrm{P}(\mathrm{dCz} 1-c o-\mathrm{dTC} 2) ; 549 \mathrm{~nm}$ and $815 \mathrm{~nm}$ for PdTC) were seen at the longer wavelengths zone. The optical band gap $\left(E_{\mathrm{g}}\right)$ values of PdCz, P(dCz2-co-dTC1), P(dCz2-co-dTC2), P(dCz1-co-dTC2), and PdTC electrodes were $3.01,2.43,2.48,2.42$, and $2.45 \mathrm{eV}$, respectively. 

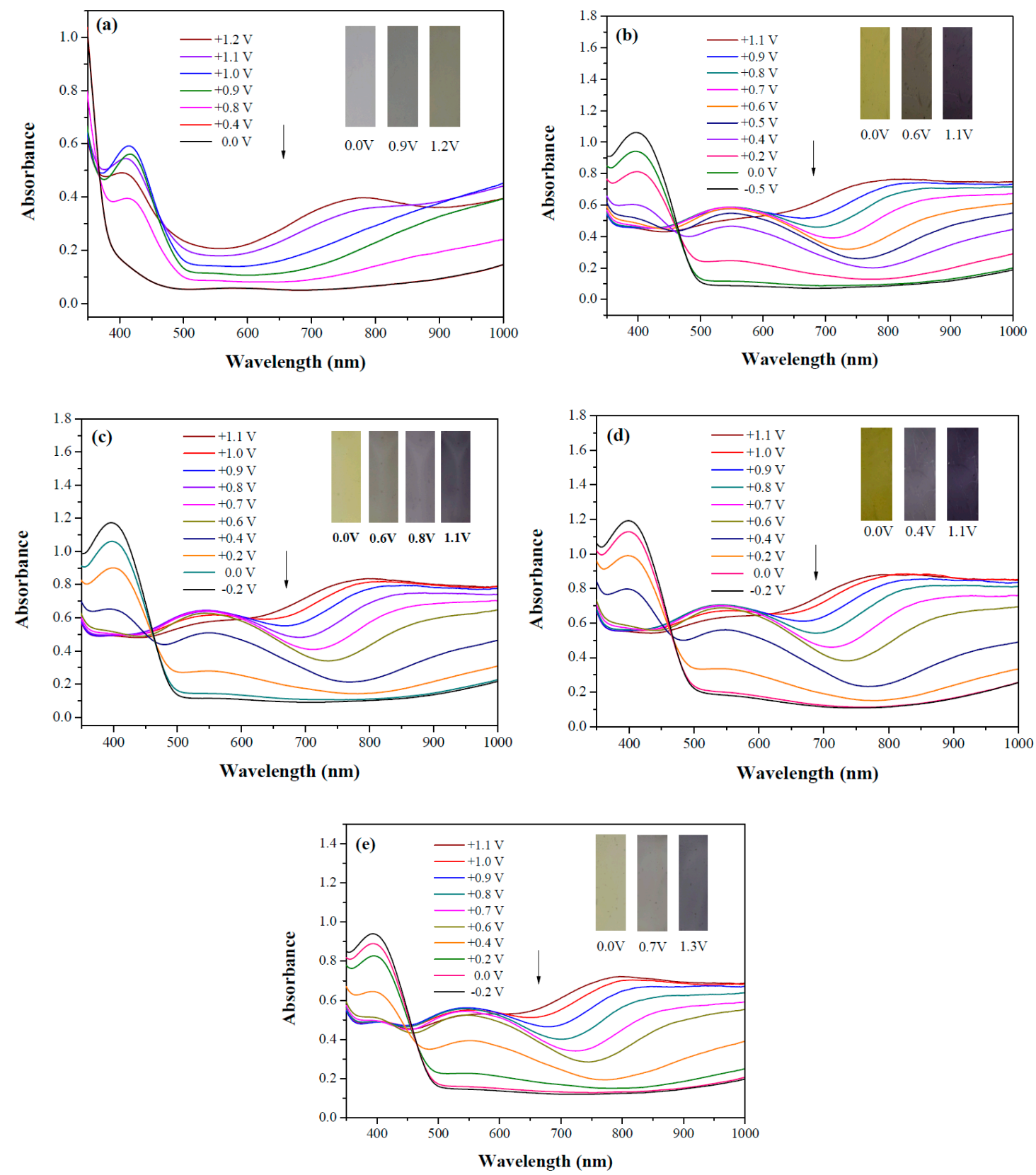

Figure 5. UV-Visible spectra of (a) PdCz; (b) P(dCz2-co-dTC1); (c) P(dCz2-co-dTC2); (d) P(dCz1-co-dTC2) and (e) PdTC electrodes on ITO in ACN/DCM (1:1, by volume) solution containing $0.2 \mathrm{M} \mathrm{LiClO}_{4}$.

$\mathrm{PdCz}$ displayed multichromic behaviors with a light gray color in its neutral state $(0.0 \mathrm{~V})$, an iron grey color $(0.9 \mathrm{~V})$ and a dark gray color $(1.2 \mathrm{~V})$ during stepwise oxidation. The colors of PdTC electrode were light yellowish-gray, light gray, and iron grey at $0.0,0.7$, and $1.3 \mathrm{~V}$, respectively. The dCzand dTC-containing copolymer electrodes displayed different multichromic behaviors with $\mathrm{PdCz}$ and PdTC electrodes. $\mathrm{P}(\mathrm{dCz} 2-\mathrm{co}-\mathrm{dTC} 1)$ film was yellowish green, gray, and purplish grey at 0.0 , 0.6 , and $1.1 \mathrm{~V}$, respectively, whereas $\mathrm{P}(\mathrm{dCz} 2-\mathrm{co}-\mathrm{dTC} 2)$ film was yellowish green, greenish gray, gray, and purplish gray at $0.0,0.6,0.8$, and $1.1 \mathrm{~V}$, respectively, and $\mathrm{P}(\mathrm{dCz} 1-\mathrm{co}-\mathrm{dTC} 2)$ film was yellow, gray, and dark purplish-grey at $0.0,0.4$, and $1.1 \mathrm{~V}$, respectively. The colorimetric values $\left(L^{*}, a^{*}\right.$, and $\left.b^{*}\right), \mathrm{CIE}$ (Commission Internationale de I'Eclairage) chromaticity values $(x, y)$ and diagrams of the five polymer films at various potentials are listed in Table 2. 
Table 2. Colorimetric values $\left(L^{*}, a^{*}\right.$, and $\left.b^{*}\right)$, CIE chromaticity values $(x, y)$ and diagrams of the (a) PdCz, (b) P(dCz2-co-dTC1), (c) P(dCz2-co-dTC2), (d) P(dCz1-co-dTC2), and (e) PdTC at various applied potentials.

\begin{tabular}{ccccccc}
\hline & \multicolumn{7}{c}{ (a) } \\
\hline Potential (V) & $\boldsymbol{L}^{*}$ & $\boldsymbol{a}^{*}$ & $\boldsymbol{b}^{*}$ & $\boldsymbol{x}$ & $\boldsymbol{y}$ & Diagram \\
\hline 0.0 & 95.12 & -0.34 & 2.95 & 0.4500 & 0.4106 \\
\hline 0.8 & 92.64 & -1.33 & 18.74 & 0.4638 & 0.4258 \\
\hline 0.9 & 90.35 & -1.99 & 25.66 & 0.4692 & 0.4328 \\
\hline 1.0 & 87.76 & -3.07 & 23.96 & 0.4664 & 0.4334 \\
\hline 1.2 & 84.27 & -4.52 & 18.11 & 0.4588 & 0.4311
\end{tabular}

(b)

\begin{tabular}{ccccccc}
\hline Potential (V) & $\boldsymbol{L}^{*}$ & $\boldsymbol{a}^{*}$ & $\boldsymbol{b}^{*}$ & $\boldsymbol{x}$ & $\boldsymbol{y}$ & Diagram \\
\hline-0.5 & 90.36 & -2.48 & 41.83 & 0.4815 & 0.4456 \\
\hline 0.2 & 78.82 & 1.71 & 24.79 & 0.4775 & 0.4293 \\
\hline 0.4 & 64.49 & 5.65 & 1.11 & 0.4612 & 0.3999 \\
\hline 0.8 & 56.45 & 6.50 & -7.41 & 0.4509 & 0.3859 \\
\hline 1.1 & 58.22 & -2.34 & -8.72 & 0.4284 & 0.3987 & \\
\hline
\end{tabular}

(c)

\begin{tabular}{ccccccc}
\hline Potential (V) & $\boldsymbol{L}^{*}$ & $\boldsymbol{a}^{*}$ & $\boldsymbol{b}^{*}$ & $\boldsymbol{x}$ & $\boldsymbol{y}$ & Diagram \\
\hline-0.2 & 87.82 & -1.08 & 35.11 & 0.4793 & 0.4395 & \\
\hline 0.2 & 65.75 & 4.92 & 1.02 & 0.4593 & 0.4011 \\
\hline 0.8 & 57.30 & 5.37 & -6.45 & 0.4498 & 0.3893 \\
\hline 0.9 & 56.84 & 3.41 & -6.98 & 0.4444 & 0.3916 & \\
\hline 1.1 & 57.99 & -3.38 & -8.82 & 0.4258 & 0.4002 & \\
\hline
\end{tabular}

(d)

\begin{tabular}{|c|c|c|c|c|c|c|}
\hline Potential (V) & $L^{*}$ & $a^{*}$ & $b^{*}$ & $x$ & $y$ & Diagram \\
\hline-0.2 & 85.42 & 0.44 & 42.42 & 0.4883 & 0.4432 & \\
\hline 0.2 & 75.20 & 3.48 & 26.48 & 0.4836 & 0.4287 & \\
\hline 0.6 & 54.48 & 7.37 & -6.51 & 0.4546 & 0.3851 & \\
\hline 0.9 & 53.03 & 4.21 & -6.75 & 0.4466 & 0.3898 & \\
\hline 1.1 & 55.04 & -1.72 & -7.61 & 0.4309 & 0.3990 & \\
\hline
\end{tabular}

(e)

\begin{tabular}{ccccccc}
\hline Potential (V) & $\boldsymbol{L}^{*}$ & $\boldsymbol{a}^{*}$ & $\boldsymbol{b}^{*}$ & $\boldsymbol{x}$ & $\boldsymbol{y}$ & Diagram \\
\hline-0.2 & 87.95 & -1.58 & 31.51 & 0.4754 & 0.4374 & \\
\hline 0.2 & 82.07 & 0.27 & 22.50 & 0.4719 & 0.4287 \\
\hline 0.6 & 65.32 & 5.12 & -2.87 & 0.4543 & 0.3960 \\
\hline 0.9 & 61.22 & 5.69 & -5.11 & 0.4525 & 0.3915 \\
\hline 1.1 & 61.51 & -0.69 & -6.32 & 0.4366 & 0.3999 & \\
\hline
\end{tabular}

\subsection{Electrochromic Switching of Polymer Electrodes}

As displayed in Figure 6, PdCz, P(dCz2-co-dTC1), P(dCz2-co-dTC2), P(dCz1-co-dTC2), and PdTC films were monitored by potential stepping between neutral $(0.0 \mathrm{~V})$ and oxidized states $(+1.1 \mathrm{~V})$ with a residence time of $10 \mathrm{~s}$. The $\Delta T$ values of PdCz, P(dCz2-co-dTC1), P(dCz2-co-dTC2), P(dCz1-co-dTC2), 
and PdTC films were $19.7 \%$ at $790 \mathrm{~nm}, 55.7 \%$ at $790 \mathrm{~nm}, 57.0 \%$ at $784 \mathrm{~nm}, 50.6 \%$ at $790 \mathrm{~nm}$, and $48.0 \%$ at $790 \mathrm{~nm}$, respectively. The $\Delta T$ of $\mathrm{P}(\mathrm{dCz} 2-\mathrm{co}-\mathrm{dTC} 1), \mathrm{P}(\mathrm{dCz} 2-\mathrm{co}-\mathrm{dTC} 2)$, and $\mathrm{P}(\mathrm{dCz} 1-\mathrm{co}-\mathrm{dTC} 2)$ films were larger than those of $\mathrm{PdCz}$ and PdTC films in $0.2 \mathrm{M} \mathrm{LiClO}_{4} / \mathrm{ACN} / \mathrm{DCM}$ solution, indicating copolymers contain both $\mathrm{dCz}$ and dTC units increased $\Delta T$ significantly. The $\tau_{\mathrm{c}}$ of electrodes (a), (b), (c), (d), and (e) were $4.0 \mathrm{~s}, 2.7 \mathrm{~s}, 3.5 \mathrm{~s}, 4.2 \mathrm{~s}$, and $4.3 \mathrm{~s}$ at $3 \mathrm{rd}$ cycles, respectively, and the $\tau_{\mathrm{b}}$ of electrodes (a), (b), (c), (d), and (e) were $0.8 \mathrm{~s}, 2.7 \mathrm{~s}, 1.8 \mathrm{~s}, 5.6 \mathrm{~s}$, and $6.0 \mathrm{~s}$ at $3 \mathrm{rd}$ cycles, respectively. Different $\tau_{\mathrm{c}}$ and $\tau_{\mathrm{b}}$ in each set of samples may be attributed to the contact area between electrolytes and electrodes.

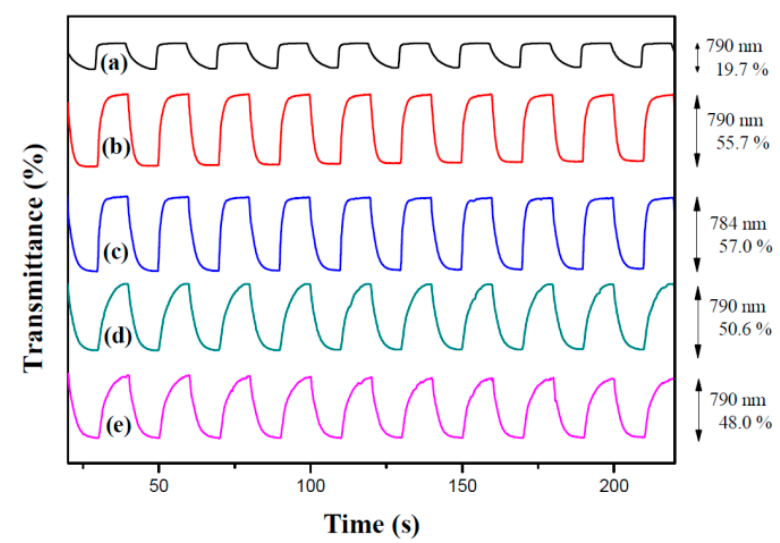

Figure 6. Optical contrast of (a) PdCz; (b) P(dCz2-co-dTC1); (c) P(dCz2-co-dTC2); (d) P(dCz1-co-dTC2) and (e) PdTC electrodes in an ACN/DCM (1:1, by volume) solution containing $0.2 \mathrm{M} \mathrm{LiClO}_{4}$ with a residence time of $10 \mathrm{~s}$.

$\Delta \mathrm{OD}$ can be determined using the formula [31],

$$
\Delta \mathrm{OD}=\log \left(\frac{T_{\text {ox }}}{T_{\text {red }}}\right)
$$

where $T_{\text {ox }}$ and $T_{\text {red }}$ are the transmittances in the oxidized and the reduced state, respectively.

The coloration efficiency $(\eta)$ is another important parameter for practical application of polymer films in ECDs and it can be determined using the equation [32]:

$$
\eta=\frac{\Delta \mathrm{OD}}{Q_{\mathrm{d}}}
$$

where $\triangle \mathrm{OD}$ is the discrepancy of optical density, $Q_{\mathrm{d}}$ implicates the amount of injected charges per unit electrode area. The $\eta$ values of PdCz, P(dCz2-co-dTC1), P(dCz2-co-dTC2), P(dCz1-co-dTC2), and PdTC films are $81.4 \mathrm{~cm}^{2} \mathrm{C}^{-1}$ at $790 \mathrm{~nm}, 99.3 \mathrm{~cm}^{2} \mathrm{C}^{-1}$ at $790 \mathrm{~nm}, 248.4 \mathrm{~cm}^{2} \mathrm{C}^{-1}$ at $784 \mathrm{~nm}, 145.3 \mathrm{~cm}^{2} \mathrm{C}^{-1}$ at $790 \mathrm{~nm}$, and $164.9 \mathrm{~cm}^{2} \mathrm{C}^{-1}$ at $790 \mathrm{~nm}$, respectively (Table 3). $\mathrm{P}(\mathrm{dCz} 2-\mathrm{co}-\mathrm{dTC} 2)$ film presents the highest $\eta$ among the five polymer films.

Table 3. Optical and electrochemical properties investigated at the selected applied wavelength for the electrodes.

\begin{tabular}{cccccccccc}
\hline Electrodes & $\boldsymbol{\lambda} \mathbf{( n m})$ & $\boldsymbol{T}_{\mathbf{o x}}$ & $\boldsymbol{T}_{\text {red }}$ & $\boldsymbol{\Delta} \boldsymbol{T}$ & $\boldsymbol{\Delta O D}$ & $\mathbf{Q}_{\boldsymbol{d}}\left(\mathbf{m C ~} \mathbf{~ m}^{-\mathbf{2}}\right)$ & $\left.\eta \mathbf{( c m}^{\mathbf{2}} \mathbf{C}^{-\mathbf{1}}\right)$ & $\boldsymbol{\tau}_{\mathbf{c}}(\mathbf{s})$ & $\boldsymbol{\tau}_{\mathbf{b}}(\mathbf{s})$ \\
\hline PdCz & 790 & 69.7 & 89.3 & 19.7 & 0.11 & 1.351 & 81.4 & 4.0 & 0.8 \\
P(dCz2-co-dTC1) & 790 & 18.5 & 73.9 & 55.7 & 0.60 & 6.043 & 99.3 & 2.7 & 2.7 \\
P(dCz2-co-dTC2) & 784 & 10.7 & 67.7 & 57.0 & 0.80 & 3.221 & 248.4 & 3.5 & 1.8 \\
P(dCz1-co-dTC2) & 790 & 10.9 & 61.4 & 50.6 & 0.75 & 5.163 & 145.3 & 4.2 & 5.6 \\
PdTC & 790 & 9.1 & 57.1 & 48.0 & 0.80 & 4.851 & 164.9 & 4.3 & 6.0 \\
\hline
\end{tabular}




\subsection{Spectroelectrochemical Investigation of ECDs}

Figure 7 displays the UV-Vis spectra of dual-type PdCz/PProdot-Me $2, \quad \mathrm{P}\left(\mathrm{dCz}-\mathrm{Co}^{-}\right.$ dTC2)/PProdot-Me 2 , and PdTC/PProdot-Me 2 ECDs at different applied potentials.
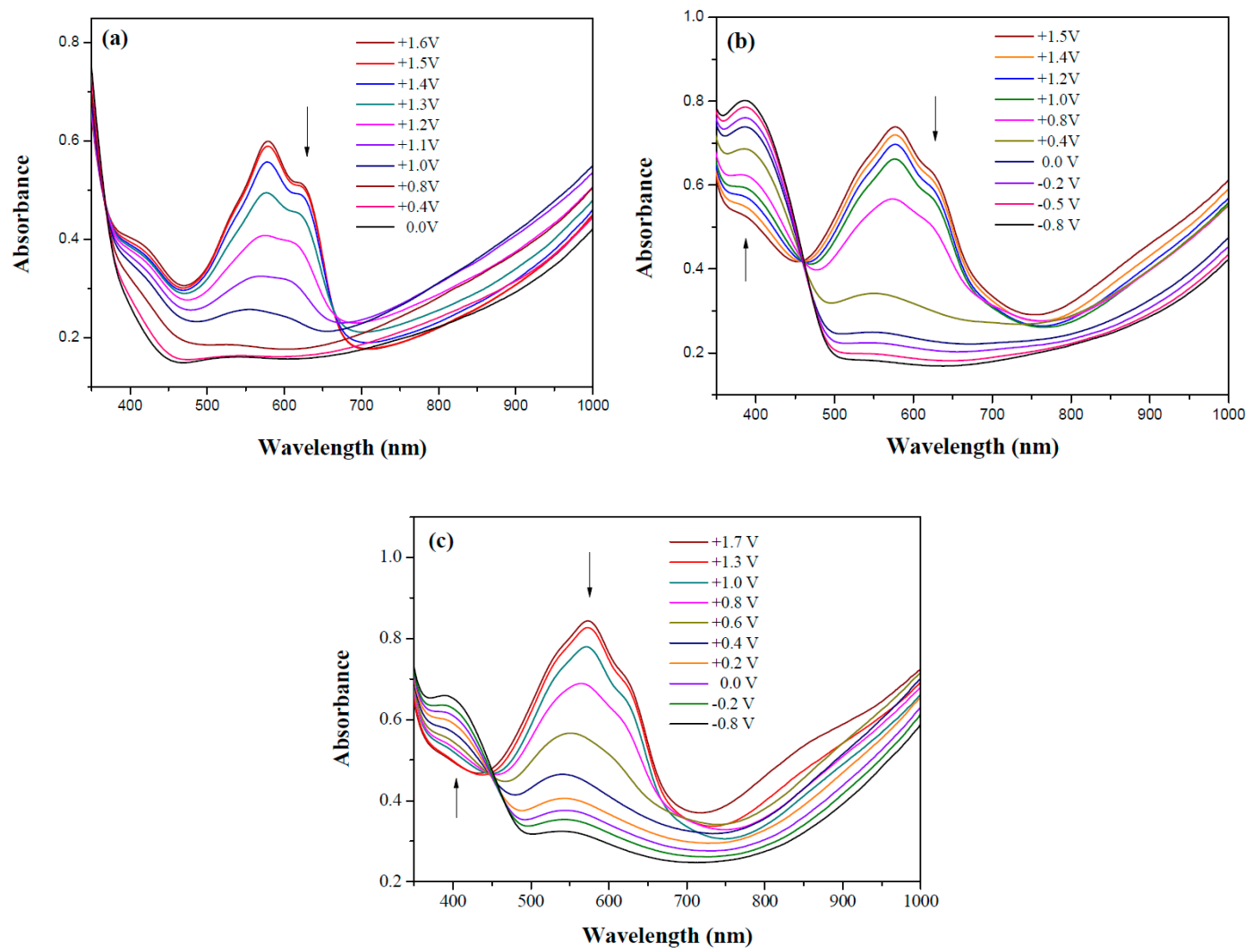

Figure 7. UV-Visible spectra of (a) PdCz/PProdot-Me 2 ; (b) $\mathrm{P}(\mathrm{dCz} 2-\mathrm{co}-\mathrm{dTC} 2) / \mathrm{PProdot}-\mathrm{Me}_{2}$ and (c) PdTC/PProdot-Me 2 ECDs.

$\mathrm{PdCz} /$ PProdot-Me $\mathrm{M}_{2} \mathrm{ECD}$ did not show distinct absorption peaks at wavelength ranging from 350 to $450 \mathrm{~nm}$ at $0.0 \mathrm{~V}, \mathrm{P}(\mathrm{dCz} 2-\mathrm{co}-\mathrm{dTC} 2) / \mathrm{PProdot}-\mathrm{Me}_{2}$ and PdTC/PProdot-Me 2 ECDs displayed distinct absorption peaks at 410 and $402 \mathrm{~nm}$ at $0.0 \mathrm{~V}$, which could be assigned as the absorption peaks of $\mathrm{P}(\mathrm{dCz} 2-\mathrm{co}-\mathrm{dTC} 2)$ and PdTC films at $0.0 \mathrm{~V}$, respectively. The absorption peaks of $\mathrm{P}(\mathrm{dCz} 2-\mathrm{co}-\mathrm{dTC} 2)$ and PdTC films fade with the increasing applied potential, and new absorption bands were emerged gradually at around $580 \mathrm{~nm}$. This can be attributed to the stepwise reduction of PProdot- $\mathrm{Me}_{2}$ film. The colors of PdCz/PProdot-Me $\mathrm{MeCD}_{2}$ are silver gray, gray, and purplish-gray at 0.0, 1.0, and $1.3 \mathrm{~V}$, respectively. $\mathrm{P}(\mathrm{dCz} 2-\mathrm{co}-\mathrm{dTC} 2) / \mathrm{PProdot}-\mathrm{Me}_{2}$ and PdTC/PProdot-Me $\mathrm{ECDs}_{2}$ reveal four kinds of colors from bleached to colored states. The colors of $\mathrm{P}(\mathrm{dCz}-\mathrm{co}-\mathrm{dTC} 2) / \mathrm{PProdot}-\mathrm{Me}_{2} \mathrm{ECD}$ are yellowish green, iron gray, dark blue, and purplish-blue at $-0.8,0.8,1.2$, and $1.5 \mathrm{~V}$, respectively. PdTC/PProdot-Me $\mathrm{M}_{2}$ ECD reveals yellowish-green, greenish-gray, grayish-blue, and purplish-blue at $-0.8,0.0,0.8$, and $1.7 \mathrm{~V}$, respectively. The electrochromic photographs, colorimetric values $\left(L^{*}, a^{*}\right.$, and $\left.b^{*}\right)$, CIE chromaticity values $(x, y)$ and diagrams of PdCz/PProdot-Me $2, \mathrm{P}(\mathrm{dCz}$-co-dTC2)/PProdot-Me, and PdTC/PProdot-Me $\mathrm{E}_{2}$ ECDs at various applied potentials are listed in Table 4. 
Table 4. Electrochromic photographs, colorimetric values $\left(L^{*}, a^{*}\right.$, and $\left.b^{*}\right)$, CIE chromaticity values $(x, y)$ and diagrams of the PdCz/PProdot-Me $e_{2}, \mathrm{P}(\mathrm{dCz} 2-\mathrm{co}-\mathrm{dTC} 2) / \mathrm{PProdot}-\mathrm{Me}_{2}$ and PdTC/PProdot-Me $\mathrm{P}_{2}$ ECDs at various applied potentials.

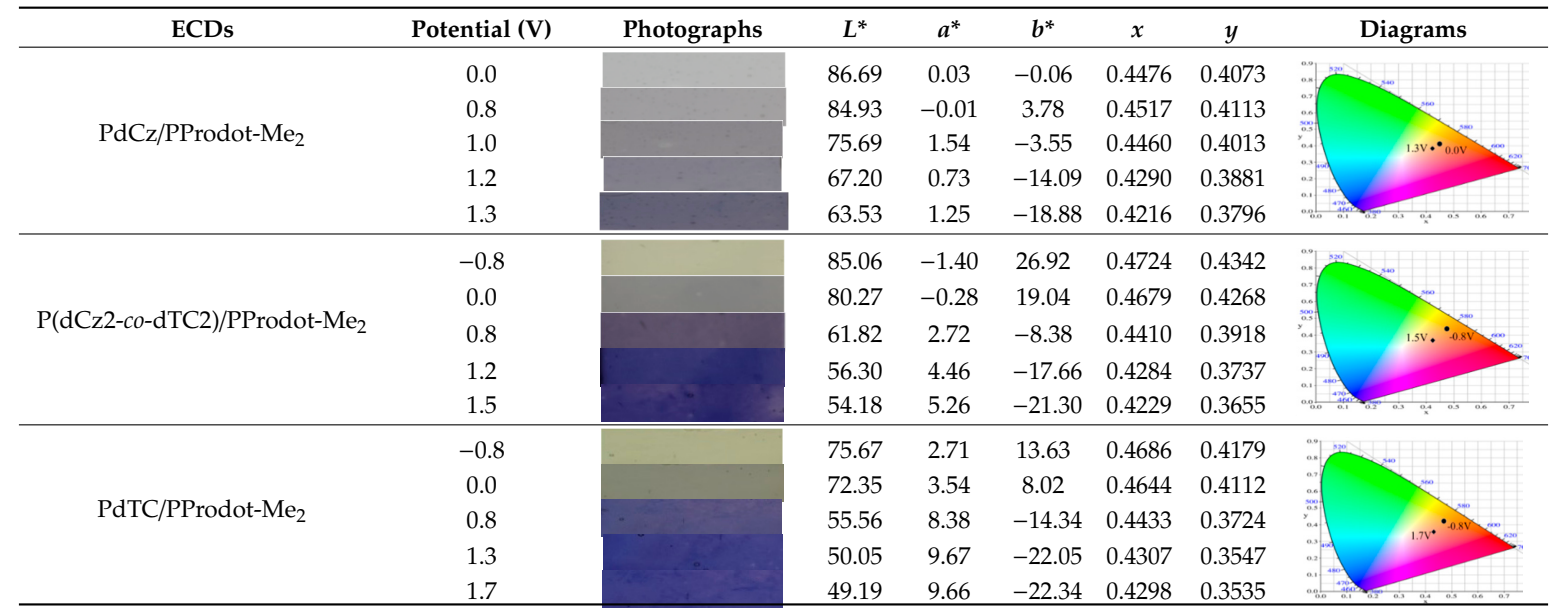

\subsection{Electrochromic Switching of ECDs}

As displayed in Figure 8, PdCz/PProdot-Me $\mathrm{P}_{2}$ and $\mathrm{P}(\mathrm{dCz} 2-\mathrm{co}-\mathrm{dTC} 2) / \mathrm{PProdot}-\mathrm{Me}_{2}$ ECDs were monitored by potential stepping between bleached and colored states with a residence time of $10 \mathrm{~s}$. The $\Delta T, \Delta \mathrm{OD}$, switching time, and $\eta$ of PdCz/PProdot-Me $\mathrm{Pe}_{2}$ $\mathrm{P}(\mathrm{dCz} 2-\mathrm{co}-\mathrm{dTC} 1) / \mathrm{PProdot}-\mathrm{Me}_{2}, \mathrm{P}(\mathrm{dCz} 2-\mathrm{co}-\mathrm{dTC} 2) / \mathrm{PProdot}-\mathrm{Me}_{2}, \mathrm{P}(\mathrm{dCz} 1-\mathrm{co}-\mathrm{dTC}$ )/PProdot-Me 2 and PdTC/PProdot- $\mathrm{Me}_{2}$ ECDs are listed in Table 5. P(dCz2-co-dTC2)/PProdot-Me 2 ECD displays the highest $\Delta T$, and $\mathrm{P}(\mathrm{dCz}-\mathrm{co}-\mathrm{dTC} 1) / \mathrm{PProdot}-\mathrm{Me}_{2}$ and $\mathrm{P}(\mathrm{dCz} 2-\mathrm{co}-\mathrm{dTC} 2) / \mathrm{PProdot}-\mathrm{Me}_{2}$ ECDs display higher $\Delta T$ and $\triangle \mathrm{OD}$ than those of PdCz/PProdot-Me $\mathrm{M}_{2}$ and PdTC/PProdot-Me $\mathrm{P}_{2}$ ECDs, indicating that the use of copolymers $(\mathrm{P}(\mathrm{dCz} 2-c o-\mathrm{dTC} 1)$ and $\mathrm{P}(\mathrm{dCz} 2-c o-\mathrm{dTC} 2))$ as the electrode materials brings about a higher $\Delta T$ at around $580 \mathrm{~nm}$ than those of homopolymers (PdCz and PdTC). Table 6 summarizes comparisons of $\Delta T$ with reported ECDs, $\mathrm{P}(\mathrm{dCz} 2-c o-\mathrm{dTC} 2) / \mathrm{PProdot}-\mathrm{Me}_{2}$ ECD shows higher $\Delta T$ than those reported for $\mathrm{P}(\mathrm{Bmco}) / \mathrm{PEDOT}$ [33], P(dNcbph)/PEDOT [34], P(tnCz1-bTp2)/PProdot-Me 2 [35], $\mathrm{p}(\mathrm{dNcbph}-\mathrm{co}-\mathrm{bth}) / \mathrm{PEDOT}$ [36], PtCz/PProDOT-Me 2 [37], and P(BCz-co-ProDOT)/triple-layer PEDOT-PSS ECDs [38]. The $\tau_{\mathrm{c}}$ and $\tau_{\mathrm{b}}$ of five ECDs in Table 5 are less than $1 \mathrm{~s}$, which are shorter than those of polymer electrodes in a solution, disclosing the ECDs change color faster than the polymers in a solution during stepwise oxidation and reduction period [39].

Table 5. Optical and electrochemical properties investigated at the selected applied wavelength for the devices.

\begin{tabular}{|c|c|c|c|c|c|c|c|c|c|}
\hline Devices & $\lambda(\mathrm{nm})$ & $T_{\mathrm{ox}}\left(\mathrm{V}^{\mathrm{a}}\right)$ & $T_{\text {red }}\left(\mathrm{V}^{\mathrm{a}}\right)$ & $\Delta T$ & $\Delta \mathrm{OD}$ & $\mathrm{Q}_{d}\left(\mathrm{mC} \mathrm{cm}^{-2}\right)$ & $\eta\left(\mathrm{cm}^{2} \mathrm{C}^{-1}\right)$ & $\tau_{\mathrm{c}}(\mathrm{s})$ & $\tau_{\mathrm{b}}(\mathrm{s})$ \\
\hline $\mathrm{P}(\mathrm{dCz} 2-\mathrm{co}-\mathrm{dTC} 1) / \mathrm{PProdot}^{-\mathrm{Me}_{2}}$ & 580 & $15.1(1.5)$ & $55.2(-0.8)$ & 40.1 & 0.563 & 1.001 & 562.4 & 0.3 & 0.2 \\
\hline $\mathrm{P}(\mathrm{dCz} 1-\mathrm{co}-\mathrm{dTC} 2) / \mathrm{PProdot}^{-\mathrm{Me}_{2}}$ & 578 & $36.8(1.5)$ & $69.0(-0.8)$ & 32.2 & 0.273 & 0.622 & 438.9 & 0.9 & 0.2 \\
\hline PdTC/PProdot- $\mathrm{Me}_{2}$ & 578 & $15.6(1.5)$ & $46.8(-0.8)$ & 31.2 & 0.477 & 1.083 & 440.4 & 0.2 & 0.2 \\
\hline
\end{tabular}

a The selected applied voltages for the devices. 

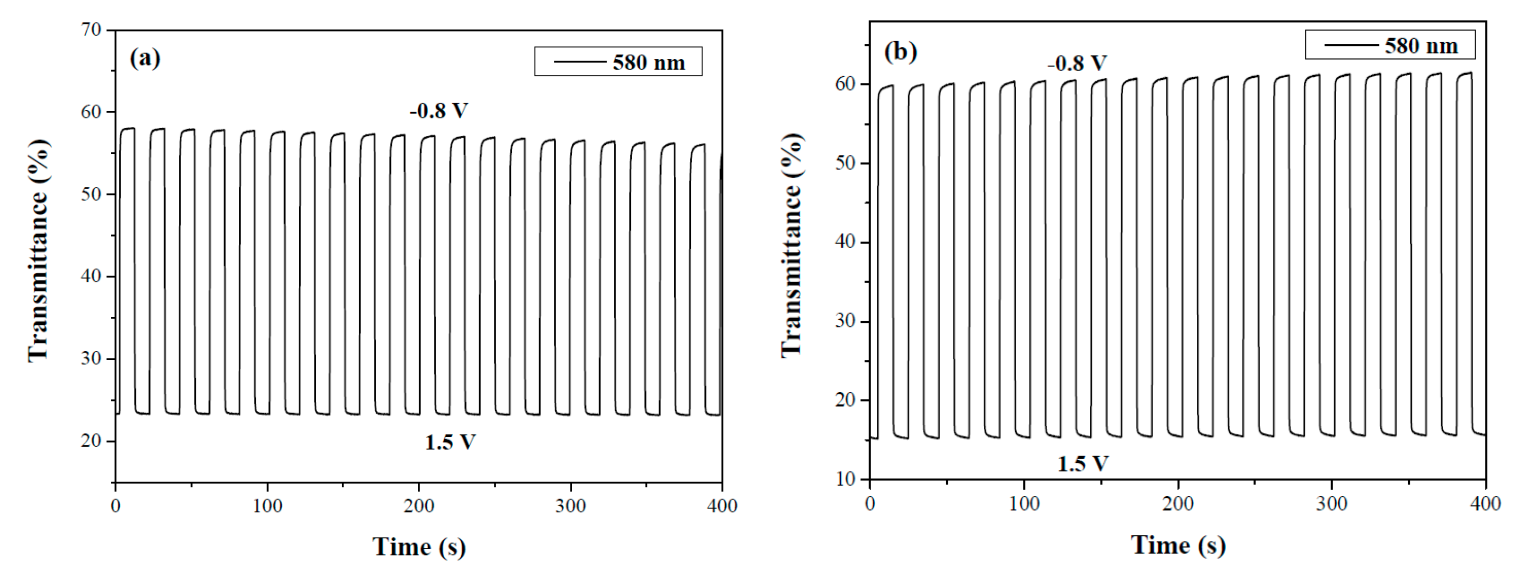

Figure 8. Optical contrast of (a) PdCz/PProdot-Me 2 and (b) P(dCz2-co-dTC2)/PProdot-Me $\mathrm{E}_{2}$ ECDs with a residence time of $10 \mathrm{~s}$.

The $\eta$ of PdCz/PProdot-Me $2, \mathrm{P}(\mathrm{dCz} 2-\mathrm{co}-\mathrm{dTC} 1) / \mathrm{PProdot}-\mathrm{Me}_{2}, \mathrm{P}(\mathrm{dCz} 2-\mathrm{co}-\mathrm{dTC}) / \mathrm{PProdot}-\mathrm{Me}_{2}$, $\mathrm{P}\left(\mathrm{dCz1}-\mathrm{co}-\mathrm{dTC}\right.$ )/PProdot-Me ${ }_{2}$ and PdTC/PProdot-Me $\mathrm{P}_{2}$ ECDs were 507.0, 562.4, 528.8, 438.9 and $440.4 \mathrm{~cm}^{2} \mathrm{C}^{-1}$, respectively. $\mathrm{P}(\mathrm{dCz} 2-\mathrm{co}-\mathrm{dTC} 1)$ film with a $\mathrm{dCz} / \mathrm{dTC}=2 / 1$ feed molar ratio presented the highest $\eta$ among the five ECDs. Table 6 also summarizes comparisons of $\eta$ with reported ECDs: $\mathrm{P}(\mathrm{dCz} 2-\mathrm{co}-\mathrm{dTC} 2) / \mathrm{PProdot}-\mathrm{Me}_{2}$ ECD showed higher $\eta$ than those reported for $\mathrm{p}(\mathrm{dNcbph}-\mathrm{co}$-bth)/PEDOT [36], PtCz/PProDOT-Me2 [37], and P(BCz-co-ProDOT)/triple-layer PEDOT-PSS ECDs [38]. However, $\mathrm{P}(\mathrm{dCz} 2-\mathrm{co}-\mathrm{dTC}) / \mathrm{PProdot}-\mathrm{Me}_{2}$ ECD showed lower $\eta$ than that reported for $\mathrm{P}(\mathrm{tnC} \mathrm{z} 1-\mathrm{bT}$ 2) $) / \mathrm{PProdot}-\mathrm{Me}_{2} \mathrm{ECD}$ [35].

Table 6. Optical contrast and coloration efficiencies of some ECDs.

\begin{tabular}{|c|c|c|c|}
\hline ECD Configuration & $\Delta T_{\max }(\%)$ & $\eta\left(\mathrm{cm}^{2} \mathrm{C}^{-1}\right)$ & Ref. \\
\hline $\mathrm{P}(\mathrm{Bmco}) / \mathrm{PEDOT}$ & $35(620 \mathrm{~nm})$ & - & [33] \\
\hline $\mathrm{P}(\mathrm{dNcbph}) / \mathrm{PEDOT}$ & $19(550 \mathrm{~nm})$ & - & {$[34]$} \\
\hline $\mathrm{P}(\operatorname{tnC} \mathrm{z} 1-\mathrm{bTp} 2) / \mathrm{PProdot}-\mathrm{Me}_{2}$ & $40(630 \mathrm{~nm})$ & $539(630 \mathrm{~nm})$ & [35] \\
\hline $\mathrm{p}(\mathrm{dNcbph}-\mathrm{co}-\mathrm{bth}) / \mathrm{PEDOT}$ & $28.6(700 \mathrm{~nm})$ & $234(700 \mathrm{~nm})$ & [36] \\
\hline PtCz/PProDOT-Me $\mathrm{Me}_{2}$ & $36(572 \mathrm{~nm})$ & $343.4(572 \mathrm{~nm})$ & [37] \\
\hline P(BCz-co-ProDOT)/triple-layer PEDOT-PSS & $41(642 \mathrm{~nm})$ & $417(642 \mathrm{~nm})$ & [38] \\
\hline $\mathrm{P}(\mathrm{dCz} 2-c o-\mathrm{dTC} 2) /$ PProdot- $\mathrm{Me}_{2}$ & $45.8(580 \mathrm{~nm})$ & $528.8(580 \mathrm{~nm})$ & This work \\
\hline
\end{tabular}

\subsection{Open-Circuit Memory of ECDs}

The open-circuit memory effect of PdCz/PProdot-Me ${ }_{2}, \mathrm{P}(\mathrm{dCz} 2-\mathrm{co}-\mathrm{dTC} 2) / \mathrm{PProdot}-\mathrm{Me}_{2}$, and PdTC/PProdot-Me $\mathrm{M}_{2}$ ECDs was detected at bleached and colored states by applying the voltage for $1 \mathrm{~s}$ for each $100 \mathrm{~s}$ interval $[40,41]$. Figure 9 shows that the transmittance of the three ECDs was almost no change at the bleached state. At colored states, the three ECDs were less stable than those at bleached state. However, the loss in transmittance of ECDs at colored states was less than $4 \%$. It is worth mentioning that $\mathrm{P}(\mathrm{dCz} 2-c o-\mathrm{dTC} 2) / \mathrm{PProdot}-\mathrm{Me}_{2}$ ECD showed less transmittance change at the colored state than those of PdCz/PProdot-Me ${ }_{2}$ and PdTC/PProdot-Me $\mathrm{ECD}_{2}$, disclosing that $\mathrm{P}(\mathrm{dCz} 2-\mathrm{co}-\mathrm{dTC} 2) / \mathrm{PProdot}-\mathrm{Me}_{2}$ ECD exhibited a satisfactory open-circuit memory effect. 

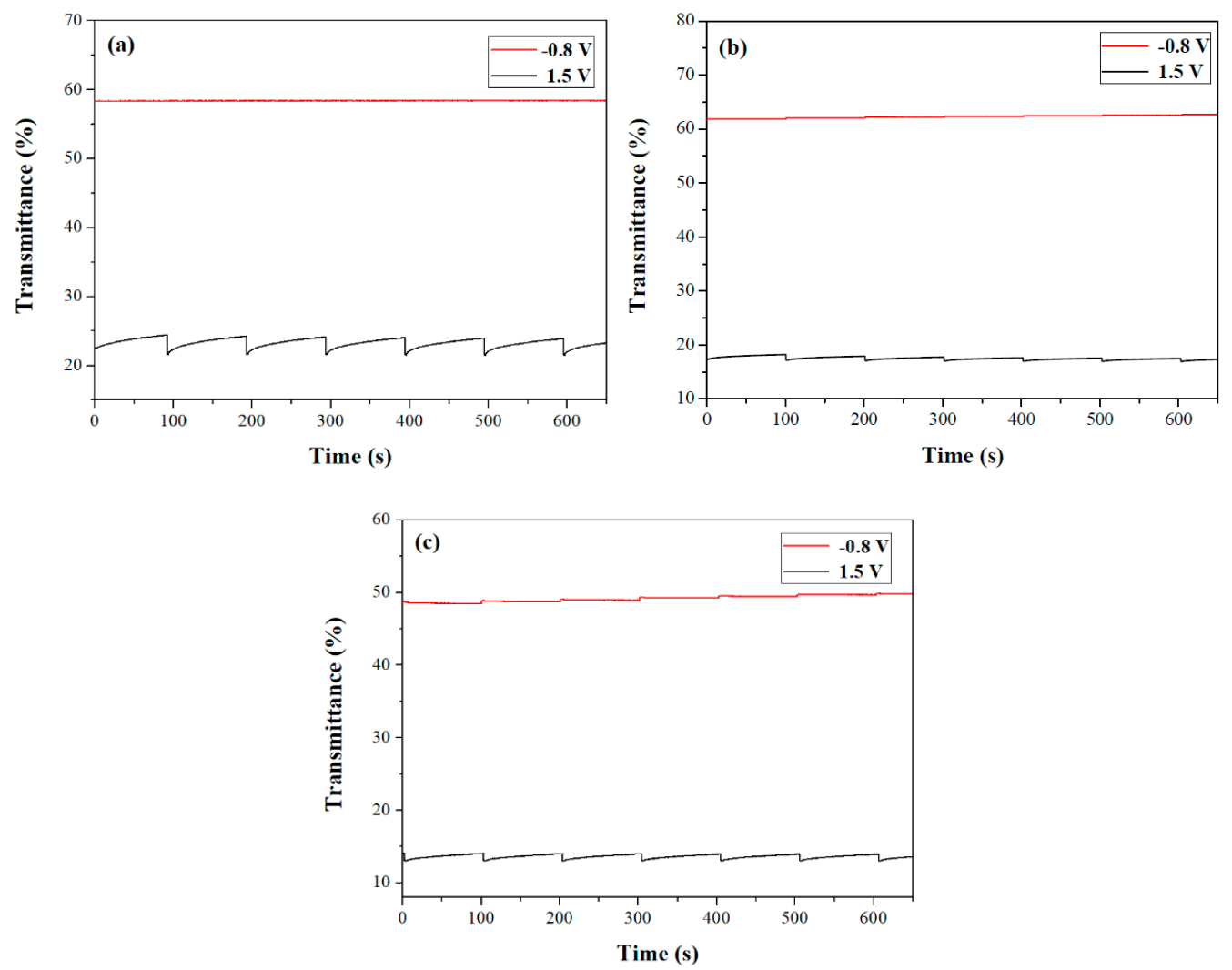

Figure 9. Open circuit stability of (a) PdCz/PProdot-Me 2 ; (b) $\mathrm{P}(\mathrm{dCz} 2-\mathrm{co}-\mathrm{dTC} 2) / \mathrm{PProdot}-\mathrm{Me}_{2}$ and (c) PdTC/PProdot-Me 2 ECDs.

\subsection{Electrochemical Stability of ECDs}

The long-term electrochemical stability of PdCz/PProdot-Me $\mathrm{P}_{2} \mathrm{P}(\mathrm{dCz} 2-\mathrm{co}-\mathrm{dTC}) / \mathrm{PProdot}-\mathrm{Me}_{2}$, and PdTC/PProdot-Me 2 ECDs was monitored using CV at the 1st, 500th and 1000th cycles [42]. From the observation of ECDs' electrochemical ability in Figure 10,78.4\%, 95.5\%, and 87.7\% of electroactive stability were preserved at the 500 th cycle, and $72.5 \%, 88.0 \%$, and $78.2 \%$ of electroactive stability were preserved at the 1000th cycle for PdCz/PProdot-Me $2, \mathrm{P}(\mathrm{dCz} 2-c o-d T C 2) / P P r o d o t-\mathrm{Me}_{2}$, and PdTC/PProdot-Me 2 ECDs, respectively. $\mathrm{P}(\mathrm{dCz} 2-c o-\mathrm{dTC} 2) / \mathrm{PProdot}-\mathrm{Me}_{2} \mathrm{ECD}$ showed better long-term electrochemical stability than those of PdCz/PProdot-Me $\mathrm{P}_{2}$ and PdTC/PProdot-Me ${ }_{2}$ ECDs, disclosing the redox stability of copolymerized $\mathrm{P}(\mathrm{dCz} 2-\mathrm{co}-\mathrm{dTC} 2)$ film was higher than those of homopolymerized PdCz and PdTC films and ECD employed a copolymer $(\mathrm{P}(\mathrm{dCz} 2-\mathrm{co}-\mathrm{dTC} 2))$ as anodic polymer film gave rise to a better long-term electrochemical stability than those of homopolymers (PdCz and PdTC).
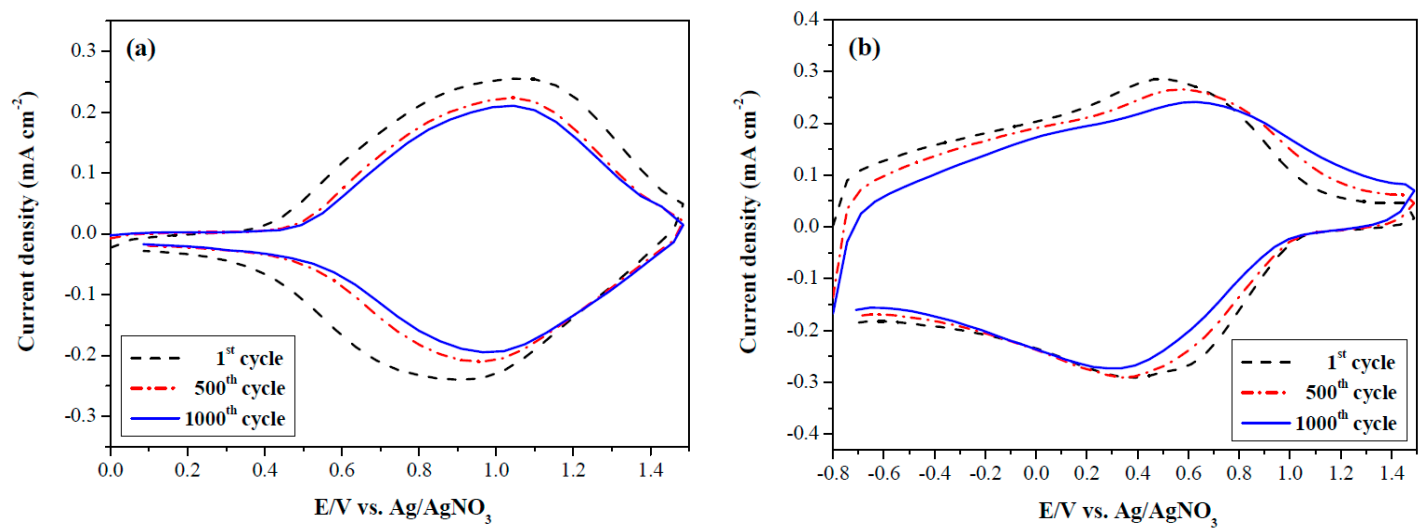

Figure 10. Cont. 


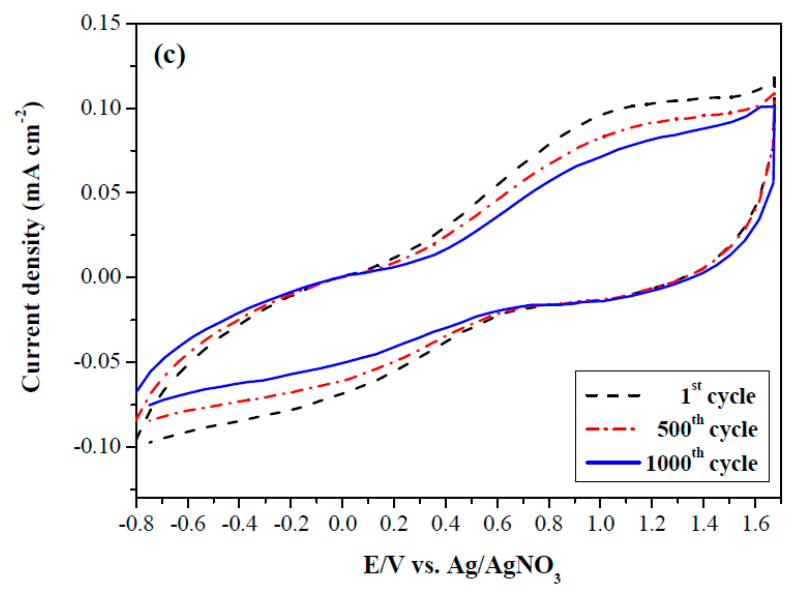

Figure 10. Cyclic voltammograms of (a) PdCz/PProdot-Me 2 ; (b) $\mathrm{P}(\mathrm{dCz} 2-\mathrm{co}-\mathrm{dTC} 2) / \mathrm{PProdot}-\mathrm{Me}_{2}$ and (c) PdTC/PProdot-Me $\mathrm{M}_{2}$ ECDs at a scan rate of $500 \mathrm{mV} \mathrm{s}^{-1}$ between one and 1000 cycles.

\section{Conclusions}

Five ECDs' polymer electrodes (PdCz, P(dCz2-co-dTC1), P(dCz2-co-dTC2), P(dCz1-co-dTC2), and PdTC) were prepared using electrochemical copolymerization. Our experimental studies display that dCz- and dTC-containing copolymer electrodes showed multichromic behaviors and the electrochromic switching properties and coloration efficiency of the copolymers could be adjusted by various feed monomer molar ratios. $\mathrm{P}(\mathrm{dCz} 2-\mathrm{co}-\mathrm{dTC} 1)$ film was yellowish green, gray, and purplish grey at $0.0,0.6$, and $1.1 \mathrm{~V}$, respectively, whereas $\mathrm{P}(\mathrm{dCz} 2-c o-\mathrm{dTC} 2)$ film was yellowish green, greenish gray, gray, and purplish gray at $0.0,0.6,0.8$, and $1.1 \mathrm{~V}$, respectively. $\mathrm{P}(\mathrm{dCz} 2-\mathrm{co}-\mathrm{dTC} 2)$ film displayed a high $\Delta T(57.0 \%)$ and a high $\eta\left(248.4 \mathrm{~cm}^{2} \mathrm{C}^{-1}\right)$ at $784 \mathrm{~nm}$ in $0.2 \mathrm{M} \mathrm{LiClO}_{4} / \mathrm{ACN} / \mathrm{DCM}$ solution. Five ECDs based on dCz- and dTC-containing anodic polymer electrodes and PProdot-Me $\mathrm{M}_{2}$ cathodic polymer electrodes were built and electrochromic properties were characterized. $\mathrm{P}(\mathrm{dCz}-\mathrm{co}-\mathrm{dTC}) / \mathrm{PProdot}-\mathrm{Me}_{2}$ ECD exhibited a high $\Delta T(45.8 \%$ at $580 \mathrm{~nm})$ and high long-term electrochemical stability, whereas $\mathrm{P}(\mathrm{dCz}-\mathrm{co}-\mathrm{dTC} 1) / \mathrm{PProdot}-\mathrm{Me}_{2}$ ECD exhibited high $\eta\left(562.4 \mathrm{~cm}^{2} \mathrm{C}^{-1}\right.$ at $\left.580 \mathrm{~nm}\right)$ and a rapid switching time $(\leq 0.3 \mathrm{~s})$. In view of the above studies, $\mathrm{dCz}$ - and $\mathrm{dTC}$-containing copolymers are amenable for use in ECDs.

Author Contributions: C.-W.K. conceived the research topic. Y.-T.H., J.-C.C., and T.-Y.W. carried out the experiments. C.-W.K., T.-Y.W., J.-C.C., L.-T.L., and J.-K.C. analysed the electrochromic properties.

Funding: This research received no external funding.

Acknowledgments: The authors thank the Ministry of Science and Technology of Republic of China for financially supporting this project.

Conflicts of Interest: The authors declare no conflict of interest.

\section{References}

1. Mortimer, R.J. Electrochromic materials. Annu. Rev. Mater. Res. 2011, 41, 241-268. [CrossRef]

2. Baetens, R.; Jelle, B.P.; Gustavsen, A. Properties, requirements and possibilities of smart windows for dynamic daylight and solar energy control in buildings: A state-of-the-art review. Sol. Energy Mater. Sol. Cells 2016, 94, 87-105. [CrossRef]

3. Camurlu, P.; Gültekin, C.; Bicil, Z. Fast switching, high contrast multichromic polymers from alkyl-derivatized dithienylpyrrole and 3,4-ethylenedioxythiophene. Electrochim. Acta 2012, 61, 50-56. [CrossRef]

4. Kuo, C.-W.; Wu, B.-W.; Chang, J.-K.; Chang, J.-C.; Lee, L.-T.; Wu, T.-Y.; Ho, T.-H. Electrochromic devices based on poly(2,6-di(9H-carbazol-9-yl)pyridine)-type polymer films and PEDOT-PSS. Polymers 2018, 10, 604. [CrossRef] 
5. Turkarslan, O.; Ak, M.; Tanyeli, C.; Toppare, L. Enhancing electrochromic properties of conducting polymers via copolymerization: Copolymer of 1-(4-fluorophenyl)-2,5-di(thiophen-2-yl)-1H-pyrrole with 3,4-ethylene dioxythiophene. J. Polym. Sci. Polym. Chem. 2007, 45, 4496. [CrossRef]

6. Wu, T.Y.; Li, W.B.; Kuo, C.W.; Chou, C.F.; Liao, J.W.; Chen, H.R.; Tseng, C.G. Study of poly(methyl methacrylate)-based gel electrolyte for electrochromic device. Int. J. Electrochem. Sci. 2013, 8, 10720-10732.

7. Hsiao, S.-H.; Liao, Y.-C. Facile synthesis of electroactive and electrochromic triptycene poly(ether-imide)s containing triarylamine units via oxidative electro-coupling. Polymers 2017, 9, 497. [CrossRef]

8. Nie, G.M.; Zhou, L.J.; Yang, H.J. Electrosynthesis of a new polyindole derivative obtained from 5-formylindole and its electrochromic properties. J. Mater. Chem. 2011, 21, 13873-13880. [CrossRef]

9. Hsiao, S.-H.; Lu, H.-Y. Electrosynthesis of aromatic poly(amide-amine) films from triphenylamine-based electroactive compounds for electrochromic applications. Polymers 2017, 9, 708. [CrossRef] [PubMed]

10. Camurlu, P. Polypyrrole derivatives for electrochromic applications. RSC Adv. 2014, 4, 55832-55845. [CrossRef]

11. Liu, J.; Mi, S.; Xu, Z.; Wu, J.; Zheng, J.; Xu, C. Solution-processable thiophene-based electrochromic polymers bearing trifluoromethyl rather than long side chains. Org. Electron. 2016, 37, 169-177. [CrossRef]

12. Çetin, G.A.; Balan, A.; Durmus, A.; Günbas, G.; Toppare, L. A new p- and n-dopable selenophene derivative and its electrochromic properties. Org. Electron. 2009, 10, 34-41. [CrossRef]

13. Yu, W.; Chen, J.; Fu, Y.; Xu, J.; Nie, G. Electrochromic property of a copolymer based on 5-cyanoindole and 3,4-ethylenedioxythiophene and its application in electrochromic devices. J. Electroanal. Chem. 2013, 700, 17-23. [CrossRef]

14. Tao, Y.; Zhang, K.; Zhang, Z.; Cheng, H.; Jiao, C.; Zhao, Y. Synthesis, characterizations and electrochromic properties of polymers based on functionalized anthracene. Chem. Eng. J. 2016, 293, 34-43. [CrossRef]

15. Hsiao, S.-H.; Liao, W.-K.; Liou, G.-S. Synthesis and electrochromism of highly organosoluble polyamides and polyimides with bulky trityl-substituted triphenylamine units. Polymers 2017, 9, 511. [CrossRef]

16. Lu, Q.; Cai, W.; Niu, H.; Wang, W.; Bai, X.; Hou, Y. Novel polyamides with 5H-dibenzo[b,f]azepin-5-yl-substituted triphenylamine: Synthesis and visible-NIR electrochromic properties. Polymers 2017, 9, 542. [CrossRef]

17. Guzela, M.; Karatasbz, E.; Ak, M. Synthesis and fluorescence properties of carbazole based asymmetric functionalized star shaped polymer. J. Electrochem. Soc. 2017, 164, H49-H55. [CrossRef]

18. Ouyang, M.; Fu, Z.; Lv, X.; Hu, B.; Wang, P.; Huang, S.; Dai, Y.; Zhang, C. A multichromic copolymer based on 4-(9H-carbazol-9-yl)-N,N-diphenylaniline and 3,4-ethylenedioxythiophene prepared via electrocopolymerization. J. Electrochem. Soc. 2013, 160, H787-H792. [CrossRef]

19. Feng, F.; Kong, L.; Du, H.; Zhao, J.; Zhang, J. Donor-acceptor-type copolymers based on 3,4-propylenedioxy-thiophene and 5,6-difluorobenzotriazole: Synthesis and electrochromic properties. Polymers 2018, 10, 427. [CrossRef]

20. Alkan, S.; Cutler, C.A.; Reynolds, J.R. High-quality electrochromic polythiophenes via $\mathrm{BF}_{3} \cdot \mathrm{Et}_{2} \mathrm{O}$ electropolymerization. Adv. Funct. Mater. 2003, 13, 331-336. [CrossRef]

21. Welsh, D.M.; Kumar, A.; Morvant, M.C.; Reynolds, J.R. Fast electrochromic polymers based on new poly(3,4-alkylenedioxythiophene) derivatives. Synth. Met. 1999, 102, 967-968. [CrossRef]

22. Heydari Gharahcheshmeh, M.; Gleason, K.K. Device fabrication based on oxidative chemical vapor deposition (oCVD): Synthesis of conducting polymers and related conjugated organic materials. Adv. Mater. Interfaces 2019, 6, 1801564. [CrossRef]

23. Brooke, R.; Cottis, P.; Talemi, P.; Fabretto, M.; Murphy, P.; Evans, D. Recent advances in the synthesis of conducting polymers from the vapour phase. Prog. Mater. Sci. 2017, 86, 127. [CrossRef]

24. Su, Y.-S.; Wu, T.-Y. Three carbazole-based polymers as potential anodically coloring materials for high-contrast electrochromic devices. Polymers 2017, 9, 284. [CrossRef]

25. Welsh, D.M.; Kumar, A.; Meijer, E.W.; Reynolds, J.R. Enhanced contrast ratio and rapid switching in electrochromics based on poly(3,4-propylenedioxythiophene) derivatives. Adv. Mater. 1999, 11, 1379-1382. [CrossRef]

26. Kuo, C.W.; Chen, B.K.; Li, W.B.; Tseng, L.Y.; Wu, T.Y.; Tseng, C.G.; Chen, H.R.; Huang, Y.C. Effects of supporting electrolytes on spectroelectrochemical and electrochromic properties of polyaniline-poly(styrene sulfonic acid) and poly(ethylenedioxythiophene)-poly(styrene sulfonic acid)-based electrochromic device. J. Chin. Chem. Soc. 2014, 61, 563-570. [CrossRef] 
27. Kuo, C.-W.; Wu, T.-Y.; Fan, S.-C. Applications of poly(indole-6-carboxylic acid-co-2,2'-bithiophene) films in high-contrast electrochromic devices. Coatings 2018, 8, 102. [CrossRef]

28. Ates, M.; Özyılmaz, A.T. The application of polycarbazole, polycarbazole/nanoclay and polycarbazole/Zn-nanoparticles as a corrosion inhibition for SS304 in saltwater. Prog. Org. Coat. 2015, 84, 50-58. [CrossRef]

29. Wu, T.Y.; Li, J.L. Electrochemical synthesis, optical, electrochemical and electrochromic characterizations of indene and 1,2,5-thiadiazole-based poly(2,5-dithienylpyrrole) derivatives. RSC Adv. 2016, 6, 15988-15998. [CrossRef]

30. Soganci, T.; Soyleyici, H.C.; Ak, M.; Cetisli, H. An amide substituted dithienylpyrrole based copolymer: Its electrochromic properties, physical and analytical electrochemistry, electrocatalysis, and photoelectrochemistry. J. Electrochem. Soc. 2016, 163, H59-H66. [CrossRef]

31. Wu, T.-Y.; Su, Y.-S.; Chang, J.-C. Dithienylpyrrole- and tris[4-(2-thienyl)phenyl]amine-containing copolymers as promising anodic layers in high-contrast electrochromic devices. Coatings 2018, 8, 164. [CrossRef]

32. Kuo, C.W.; Wu, T.Y.; Huang, M.W. Electrochromic characterizations of copolymers based on 4,4'-bis( $N$-carbazolyl)-1,1'-biphenyl and indole-6-carboxylic acid and their applications in electrochromic devices. J. Taiwan Inst. Chem. Eng. 2016, 68, 481-488. [CrossRef]

33. Udum, Y.A.; Hızlıateş, C.G.; Ergün, Y.; Toppare, L. Electrosynthesis and characterization of an electrochromic material containing biscarbazole-oxadiazole units and its application in an electrochromic device. Thin Solid Films 2015, 595, 61-67. [CrossRef]

34. Koyuncu, S.; Gultekin, B.; Zafer, C.; Bilgili, H.; Can, M.; Demic, S.; Kaya, I.; Icli, S. Electrochemical and optical properties of biphenyl bridged-dicarbazole oligomer films: Electropolymerization and electrochromism. Electrochim. Acta 2009, 54, 5694-5702. [CrossRef]

35. Kuo, C.W.; Lee, P.Y. Electrosynthesis of copolymers based on 1,3,5-tris( $N$-carbazolyl)benzene and 2,2'-bithiophene and their applications in electrochromic devices. Polymers 2017, 9, 518. [CrossRef] [PubMed]

36. Wang, B.; Zhao, J.; Liu, R.; Liu, J.; He, Q. Electrosyntheses, characterizations and electrochromic properties of a copolymer based on 4,4'-di(N-carbazoyl)biphenyl and 2,2'-bithiophene. Sol. Energy Mater. Sol. Cells 2011, 95, 1867-1874. [CrossRef]

37. Kuo, C.W.; Chang, J.K.; Lin, Y.C.; Wu, T.Y.; Lee, P.Y.; Ho, T.H. Poly(tris(4-carbazoyl-9-ylphenyl)amine)/three poly(3,4-ethylenedioxythiophene) derivatives complementary high-contrast electrochromic devices. Polymers 2017, 9, 543. [CrossRef]

38. Kuo, C.W.; Wu, T.L.; Lin, Y.C.; Chang, J.K.; Chen, H.R.; Wu, T.Y. Copolymers based on 1,3-bis(carbazol-9-yl)benzene and three 3,4-ethylenedioxythiophene derivatives as potential anodically coloring copolymers in high-contrast electrochromic devices. Polymers 2016, 8, 368. [CrossRef] [PubMed]

39. Kuo, C.-W.; Chang, J.-C.; Lee, P.-Y.; Wu, T.-Y.; Huang, Y.-C. Applications of electrochromic copolymers based on tris(4-carbazoyl-9-ylphenyl)amine and bithiophene derivatives in electrochromic devices. Materials 2018, 11, 1895. [CrossRef]

40. Wu, T.Y.; Su, Y.S. Electrochemical synthesis and characterization of 1,4-benzodioxan-based electrochromic polymer and its application in electrochromic devices. J. Electrochem. Soc. 2015, 162, G103-G112. [CrossRef]

41. Kuo, C.W.; Hsieh, T.H.; Hsieh, C.K.; Liao, J.W.; Wu, T.Y. Electrosynthesis and characterization of four electrochromic polymers based on carbazole and indole-6-carboxylic acid and their applications in high-contrast electrochromic devices. J. Electrochem. Soc. 2014, 161, D782-D790. [CrossRef]

42. Su, Y.S.; Chang, J.C.; Wu, T.Y. Applications of three dithienylpyrroles-based electrochromic polymers in high-contrast electrochromic devices. Polymers 2017, 9, 114. [CrossRef] [PubMed]

(C) 2019 by the authors. Licensee MDPI, Basel, Switzerland. This article is an open access article distributed under the terms and conditions of the Creative Commons Attribution (CC BY) license (http://creativecommons.org/licenses/by/4.0/). 